\title{
DOSSIÊ
}

\section{Musealização da Performatividade em Coleções Públicas e Privadas'}

\author{
Anna Paula da Silva ${ }^{2}$ \\ Emerson Dionisio Gomes de Oliveira ${ }^{3}$ \\ Fernanda Werneck Côrtes ${ }^{4}$ \\ Juliana Pereira Sales Caetano ${ }^{5}$
}

DOI |0.265 |2/museologia.v9i I8.34964

\section{Resumo}

Este texto apresenta o dossiê Musealização da Performatividade em Coleções Públicas e Privadas, cujas contribuições são de pesquisadoras e pesquisadores das áreas de Museologia, Artes Visuais, Artes Cênicas, Ciência da Informação, Comunicação, Dança, História da Arte, Antropologia, Sociologia. O objetivo do dossiê é apresentar reflexões sobre a musealização e a performatividade nas perspectivas de diferentes áreas, estabelecendo relações entre obras, narrativas, coleções públicas e privadas, cultura material, patrimônio imaterial. Para tanto, o texto está dividido em três tópicos, o documento performa, o patrimônio performa e o museu performa, contendo abordagens sobre as intersecções entre obra, documento, registro, projeto, vestígio, as formas de aquisição, a produção documental, as narrativas curatoriais, as trajetórias artísticas e institucionais e a memória coletiva, pensando a musealização como ato performativo, um processo cíclico e em constante movimento.

\section{Palavras-chave}

Musealização. Performatividade. Coleções Públicas e Privadas.

\begin{abstract}
This text presents the dossier Musealization of Performativity in Public and Private Collections, whose contributions are from researchers in the areas of Museology,Visual Arts, Performing Arts, Information Science, Communication, Dance, Art History, Anthropology, Sociology. The main aim of the dossier is to present analyses on musealization and performativity from the perspectives of different areas, establishing relationships between works, narratives, public and private collections, material culture, intangible heritage. For this purpose, the text has three topics: performing document, performing heritage, and performing museum, which presents approaches on the intersections between work, document, record, project, remains, forms of acquisition, documentary production, curatorial narratives, artistic and institutional trajectories, and collective memory, thinking of musealization as a performative act, a cyclical process in constant movement.
\end{abstract}

\section{Keywords}

Musealization. Performativity. Public and Private Collections.

I Este dossiê faz parte das atividades do Grupo de Pesquisa Musealização da Arte: Poéticas em Narrativas. E-mail: musealizacaodarte@gmail.com.

2 Professora do Departamento de Museologia da Universidade Federal da Bahia e doutoranda pelo Programa de Pós-Graduação em Artes Visuais da Universidade de Brasília (PPGAV-UnB). E-mail: anna.silva@ ufba.br. ORCID: https://orcid.org/0000-0003-1692-5502.

3 Docente da Universidade de Brasília, vinculado ao PPGCinf/UnB e ao PPGAV/UnB. Pesquisador CNPq. E-mail: dionisio@unb.br. ORCID: https://orcid.org/0000-0002-3705-1667.

4 Museóloga e mestre em Ciência da Informação pela Universidade de Brasília (UnB). E-mail: fwerneck@ gmail.com. ORCID: https://orcid.org/0000-000I-69|8-9946.

5 Museóloga e doutoranda pela Escola de Belas Artes da Universidade Federal de Minas Gerais (UFMG) E-mail: julianasalesmuseologia@gmail.com. ORCID: https://orcid.org/0000-0002-2487-4787. 
As noções sobre performatividade são discutidas em estudos de diferentes áreas como a Antropologia, o Teatro, a Dança, a Linguística, a Comunicação, os Estudos da Performance, as Artes Visuais, entre outras; e atreladas às dinâmicas sociais, históricas e culturais distintas. Em nosso campo de interesse, a intersecção interdisciplinar entre a Museologia e as Artes Visuais, interessa-nos a compreensão e a plasticidade das noções e dos conceitos que entrecortam o fenômeno da performatividade, endereçadas à musealização. Isto é, como inscrever a performatividade nas perspectivas da musealização para compreender as trajetórias de indivíduos, grupos sociais, instituições, linguagens, objetos-obras, fenômenos poéticos?

A literatura dedicada à musealização, em suas diferentes acepções, tem se dedicado à assimilação e à preservação dos fenômenos e dos bens culturais, na porosa fronteira entre a tangibilidade e a intangibilidade dos patrimônios. Nesse sentido, a reunião dos textos acolhidos e avaliados para a Revista Museologia e Interdisciplinaridade parte da junção entre a performatividade e a musealização na intenção de apresentar discussões sobre as inferências de diferentes e similares perspectivas sobre essas noções, entre aproximações e distâncias das leituras sobre as dinâmicas em coleções, obras e práticas museológicas.

Assim, a musealização é tomada como intenção, aquisição em processos contextuais-temporais de uma coleção. Sendo, portanto, ação, ato, gesto em trânsito, retroalimentados por trajetórias de objetos, de práticas e de narrativas. Quanto às narrativas, enfatizamos a relação da imaterialidade com a performatividade presente no gesto da musealização.

A performatividade é elemento-chave para a compreensão das intenções e dos processos que envolvem agentes e agências: museus, patrimônios, acervos, grupos sociais, indivíduos. É também associada à sobrevivência, inscrevendo a continuidade, a perpetuidade, a permanência vestigial. Como uma metalinguagem, uma locução que articula os sentidos e as narrativas sobre algo, na transmutação entre reiterar e romper, que se configura como ponto de conexão entre genealogias e temporalidades ${ }^{6}$. É importante destacar a performatividade como uma noção atribuída a diferentes manifestações das artes e da cultura, não apenas na arte da performance.

Neste dossiê, os textos apresentados discorrem sobre musealização e performatividade em um campo ampliado, tendo perspectivas brasileiras e estrangeiras. Os textos apresentam: reflexões dos estudos da performance; noções sobre performatividade; a musealização de vestígios; obras e práticas imateriais; problemáticas quanto aos processos de musealização; discussões acerca dos limites entre as obras e suas documentações; a performatividade da documentação e das obras; os desafios dos museus frente ao colecionamento das obras e dos processos transitivos; as possibilidades de comunicação entre a cultura imaterial e a sociedade propostas pelas instituições museológicas e patrimoniais.

\footnotetext{
6 A proposta inicial do dossiê contemplava reflexões sobre a performatividade ao encontro das práticas museológicas e museais e dos acervos, e vice-versa, visando textos que apresentassem a musealização da performatividade frente às artes visuais, aos saberes tradicionais, à dança, ao teatro, à música, às artes cênicas, e que pudessem também discorrer sobre encenação, ritual, corporeidade. Foram sugeridos quatro eixos temáticos: (I) História das políticas de preservação imaterial; (2) A noção de performatividade em coleções públicas e privadas de artes visuais, saberes tradicionais, dança, artes cênicas e música; (3) Relações entre performance, ritual e corporeidade e suas transformações; (4) A musealização da performatividade das obras/ do acervo nos processos museais e museológicos.
} 


\section{O documento performa}

Autoras e autores acolhidos nesta edição da M\&l nos ofereceram abordagens críticas do processo de musealização da performance e seus efeitos sobre diferentes obras, processos e instituições. Em Políticas e Performatividades da Memória: Museus e Performance, Daniela Salazar apresenta uma análise quanto às noções de memória, aos museus e à performance, construindo acepções sobre as dimensões temporais da memória e o caráter performativo do museu. Para a pesquisadora portuguesa, a performance contrasta da perspectiva de permanência relacionada aos museus, propondo uma atualização de suas práticas frente a questão de como assimilar as memórias fragmentadas de práticas artísticas. A autora cita os reenactments como uma possibilidade de atualizar as obras e de redocumentá-las.

Daniela Félix Martins apresenta a performatividade como a imaterialidade da ação performática, o que para autora evidencia a performance como arte efêmera. No texto, A musealização da Performance: materialidades de uma arte efêmera, a autora constitui reflexões a partir do conceito de emaranhamento (meshworks) de Tim Ingold e da obra Teias de Roberta Carvalho - projeção de imagens, nas paredes externas de casas, em Lençóis-Bahia, de mulheres mais velhas tecendo, narrando suas histórias - para pensar o processo, questionando a redução da performance à materialidade vestigial. Martins defende que o tempo de existência da performance ocorre em sua execução e dá destaque à musealização de ações performáticas por meio de performances delegadas. Para a autora, essa prática facilita a reperformance por meio do uso de notações, sem necessariamente contar com a presença física do artista. Além disso, garante uma relação próxima entre artistas e museus, fundamentalmente, no que se refere à garantia da integridade da obra e à proteção dos direitos de autoria.

A preservação da performance a partir dos processos de salvaguarda delineia-se pela instabilidade diante das características do fenômeno performativo. As interpretações, no âmbito museológico convencional, orientam-se e estão pautadas em narrativas sobre efemeridade, originalidade e singularidade, na iminência do desaparecimento de suas aparições. Helen Westgeest e Rachel Augusto, no texto Preserving the performativity of performance art while respecting ephemerality, abordam a preservação da performance a partir de estratégias e parâmetros da documentação, enfatizando a efemeridade como fator contingente das ações performáticas, sobretudo pelos vestígios atrelados às performances, que para as autoras não as substituem e confirmam a efemeridade das ações originais. Westgeest e Augusto enfatizam a documentação como ato de arquivar a memória da performance e utilizam a noção da performatividade para atribuí-la à ação em suas transformações e atualizações, à documentação por permitir acesso à ação e como sobrevivência e continuação da obra. Consideram ainda a possibilidade de compreender a performance a partir de versões e reinterpretações contrariamente às noções de singularidade e originalidade.

Nessas perspectivas dos processos de musealização, que envolvem a documentação, em A dicotomia documento ou obra de arte, Bruno Cesar Rodrigues aponta possibilidades de o museu lidar com obras e documentos de performance. Rodrigues desenvolve análise a partir de narrativas sobre as escolhas e diferenças estipuladas entre obra e documento, reconhecendo o registro como um documento que instrui, informa, prova e tem autonomia. Na mesma direção que Westgeest e Augusto, Rodrigues apresenta reflexões quanto à musealização 
dos registros a partir das distinções e escolhas atribuídas para representação e reaparição da performance, ponderando que esses registros são obras e documentos, portanto, passíveis de (re)interpretação.

Em uma outra perspectiva quanto à distinção entre obras e sua documentação, Marina Ciambra Rahe, no texto Chris Burden: da performance para o texto, desenvolve argumentação referente ao papel desempenhado pelos registros de performance na produção de sentidos sobre as ações, a partir das escolhas do artista. Rahe analisa obras de Burden a partir de imagens e textos disponíveis, nos quais o artista transpõe as suas obras performáticas para os registros. A premissa da autora opera pela autonomia do registro e pela sua transposição como elemento expressivo das ações ao vivo, apresentando novas camadas de sentidos, adaptação e atualização das obras e de suas narrativas, problematizando as distâncias e proximidades do espectador diante da ação performada e de seus registros.

Assim como Rahe, Myrto Kakara escolhe a condição do artista e seus domínios como fundamentais para questionar a adaptação, ou seja, as transformações das práticas dos museus, especificamente, no caso apresentado pela autora, da dança, performances coreografadas como acervo. Em seu texto Collecting Choreographed Performances: "We acquired a work that carries the possibility of extinction", a autora argumenta e expõe sobre os desafios dos museus em preservar performances coreografadas, elegendo o curador Pavel Pys como interlocutor. Kakara problematiza os documentos como evidência das obras, especificando o papel dos artistas na produção de sentidos desses documentos e nas estratégias dos museus em descobrir formas de preservar essas obras separadas dos corpos dos artistas. Informada pelo debate internacional, a autora aborda os principais problemas da musealização: a materialidade da obra nos documentos, ou seja, como os museus salvaguardam essas obras a partir dos registros; a transformação dessa materialidade; a delegação para a sobrevivência da obra, o que a torna independente do artista; e a identidade do museu de como lidar com esses trabalhos.

A performatividade dos registros se opõe a uma ideia restrita de visualização da ação em seu tempo presente, portanto, a performatividade também pode ser lida como elemento de transição, transformação e atualização da obra. Este é o caso apresentado por Anna Paula da Silva e Fernanda Werneck Côrtes, no texto Alteração, atualização e versão: a performatividade de Paulista/97. Embora a ação da montagem da obra realizada pelo artista Cildo Meireles seja incontornável para a compreensão de sua condição estética, Paulista/97 não é uma performance stricto sensu. Silva e Côrtes tomam a performatividade da obra a partir de seu verso. Centram-se na materialidade da obra para demonstrar sua transitividade. Assim, corrompem criticamente os preceitos que convencionalmente separam materialidade e imaterialidade. Da (des)localização, com a retirada do calçamento-obra da Avenida Paulista, até sua (re)inserção em novas condições expositivas, a obra performa e exige a performação da instituição, que buscou preservá-la, apresentando as contingências de Paulista/97 entre a sua perenidade enquanto objeto e a sua presença efêmera na Avenida Paulista.

As fronteiras entre perenidade e efemeridade também são problematizadas no texto $O$ que faz um palhaço sentado em um museu? Performances no contexto das coleções dos museus brasileiros, no qual Vivian Horta apresenta os desafios para a musealização de performances e as novas mídias, como jogos de videogame.A pesquisadora aponta casos reconhecidos nacional e internacional- 
mente, tendo como foco as obras, as perspectivas dos artistas, a aquisição de projetos e as adaptações das propostas artísticas às demandas das instituições. Horta ressalta a relevância do desenvolvimento em rede, junto às instituições, de diretrizes para aquisição, documentação, conservação e comunicação dessas obras. Na mesma linha, em Documentação de acervos de arte contemporânea: compartilhando experiências sobre acervos de artista, Mariana Estellita Lins Silva indaga a relação entre as categorias - linguagens e meios - da arte contemporânea e os processos de gestão de acervo, apresentando os méritos de visualizar as especificidades do acervo como referência fundamental para a documentação. Para tanto, a autora apresenta alguns instrumentos e a relação entre práticas documentais - tais como: dossiê, inventário, ficha catalográfica, base de dados -, como fundamentais ao processo de musealização de obras.

Já Marisa de Oliveira Mokarzel, no texto Uma coleção e dois performers:A Coleção da Universidade Federal do Pará, contextualiza a performance no âmbito das políticas de aquisição e da produção de conhecimento no espaço universitário. A coleção foi criada e idealizada, em 2010, pelo artista e curador Orlando Maneschy, envolvendo projetos, exposições, seminários, curadorias e publicações, e revela-nos o ineditismo de uma coleção que apresenta artistas e narrativas amazônicas. A autora aborda a noção de performatividade tanto a partir da transformação da coleção, como, também, pela presença de duas fotografias de dois artistas oriundos da Amazônia (Brasil e Peru). Fotografias derivadas às ações performativas que problematizam e poetizam questões de gênero e sexualidade: Impeachment (2007) de Lucia Gomes e Dolorosa (2007) de Giuseppe Campuzano.

Outra coleção é tomada como eixo de análise por Daniela Labra, no texto Performance arte, arquivos rebeldes e fósseis críticos. Labra apresenta a coleção Verbund, que transfigura para materialidade ações performáticas, considerando a relevância da produção historiográfica sobre as trajetórias de artistas e obras, em meio às distorções, coisificação e comodificação. Numa perspectiva crítica, a autora enfatiza as recusas da reprodutibilidade pelos artistas da performance, linguagem, segundo a autora, de natureza política avessa aos enquadramentos. Por meio da coleção austríaca, Labra enfatiza que as noções sobre performance estão em consonância com as impossibilidades de reprodução dessas ações por meio dos vestígios.

Já Recusas e empréstimos da repetição na performance, de Renan Marcondes, sublinha que a necessidade de historicização da performance altera as suas práticas e defende que a contestação do ato de documentar, em alguns casos, está atrelada ao seu valor simbólico como arte efêmera, aspecto ressaltado, também, por Martins, Westgeest e Augusto. Marcondes explora abordagens distintas sobre a relação da performance com o que considera suas reproduções. De um lado há autores contrários à performance em uma dinâmica de reprodutibilidade, enquanto do outro observa-se uma preconização da performance condicionada à repetição e à documentação. Diante dessas abordagens antagonistas, o pesquisador discorre sobre a instabilidade da performance frente à presença e à repetição. $O$ texto assume que é provável que da instabilidade possa surgir uma reinvenção de arquivos e de museus.

Nessa perspectiva,Anne Bénichou e Marie Tissot discorrem sobre o trabalho da Fondation du doute, de Watermill Center e do Musée de la danse para discutir propostas de novos formatos de instituições museológicas dedicadas à preservação, à mediação e ao conhecimento de práticas de artes performati- 
vas. Em Creating Arenas for Social Interactions: “Boundary Collections”, Bénichou e Tissot frisam o envolvimento do público, dos curadores e dos artistas a partir da utilização de objetos materiais e imateriais, em uma leitura performativa das "coleções de fronteira"- termo proposto pelas autoras a partir da noção de "objetos de fronteira" de Susan Leigh Star e James R. Griesemer - dessas instituições; e do caráter propositivo da produção de conhecimento, do engajamento dos atores e da interação social entre eles. Nesse sentido, Bénichou e Tissot inscrevem a performatividade como método de interpretação nas práticas institucionais e de construção coletiva de narrativas sobre as coleções.

\section{O patrimônio performa}

Diferentes abordagens tomaram o sentido extenso de Patrimônio para debater a performatividade e sua inserção em espaços e dimensões museológicas particulares, dando a artistas e educadores a chance de revisitar culturas, ainda hoje, tomadas à margem das grandes narrativas orientadoras das instituições de salvaguarda. Em Musealizar a queda, Felipe Ribeiro propõe uma discussão decolonial quanto à patrimonialização de monumentos dedicados ao elogio e à exaltação do passado colonialista e escravocrata. $O$ autor debate a performatividade pública e ativista do movimento Black Lives Matter como propositor das quedas de esculturas públicas em diferentes países. Movimento responsável por uma abordagem da história pela perspectiva decolonial, que mira expor a coabitação de uma história oficial edificada com toda uma cultura escravagista e sua respectiva violência. Ribeiro debate o papel do museu, diante da oportunidade de produzir novas narrativas, empenhadas não no encômio das memórias elitistas, mas na denúncia de sua brutalidade. A performatividade proposta por Ribeiro é endereçada ao movimento dos grupos na deposição dos monumentos, de forma a recusar o protagonismo da branquitude e musealizar as quedas como escritura de uma história de resistência da pretitude.

A patrimonialização, também, ocupa o cerne da pesquisa de Elizabete de Castro Mendonça. A autora explora como a preservação do patrimônio imaterial tem apresentado estratégias e instrumentos para a realização da salvaguarda por grupos sociais e instituições culturais. Em Museu, patrimônio imaterial e performance: desafios dos processos de documentação para a salvaguarda de bens registrados, Mendonça apresenta as relações entre a musealização e a patrimonialização na preservação de bens culturais intangíveis. A autora discorre sobre a documentação das matrizes de samba do Rio de Janeiro por meio de sua performatividade. Em um contexto próprio, a autora parte de duas perspectivas: equiparar os vestígios e as performances como objetos museais e museológicos e; inserir os artistas não apenas como meros informantes, mas como documentalistas do bem cultural.

A performatividade da experiência e da mediação pedagógicas é o tema o texto de Jenny González Muñoz. Neste caso, a cultura dos povos originários da Venezuela delineadas no âmbito das oficinas para professores e estudantes de séries iniciais. Em Experiencias educativas de integración comunitaria:Abordajes a la cultura inmaterial de pueblos originarios venezolanos, a autora ressalta a necessidade do reconhecimento, difusão e promoção das práticas culturais de comunidades indígenas. As oficinas foram realizadas em parceria com museus, escolas e outros espaços de memória, utilizando acervos etnográficos, de coleções públicas e privadas. Muñoz defende a importância do trabalho com objetos 
de cultura material como forma de preservação de conhecimentos e do compartilhamento de memórias sobre práticas imateriais, com o auxílio da presença dos museus nessas comunidades. Desta forma, os processos de compreensão dessas memórias são atravessados pelas subjetividades e coletividades partilhadas pelos sujeitos.

A experiência apresentada por Jezulino Lúcio Mendes Braga, em Performance e sacralidade nas exposições do MUQUIFU, converge com as narrativas de Muñoz, em termos de cultura material e das relações com os grupos sociais. Braga apresenta a musealização de um instrumento musical, Caixa de Congo e Moçambiques, pelo Museu dos Quilombos e Favelas Urbanos (MUQUIFU), e as negociações no uso desse objeto musealizado na festa do Congado no Aglomerado Santa Lúcia, pelos membros da Irmandade de Nossa Senhora do Rosário e de Santa Efigênia, em 2018.

Em A musealização dos escombros: Turvações Estratigráficas entre o saque e a ruína, Clarissa Diniz e Yuri Firmeza apresentam as implicações do Projeto Porto Maravilha, na cidade do Rio de Janeiro, elegendo o Museu de Arte do Rio (MAR) como ponto de inflexão. $O$ texto problematiza as contingências do espaço urbano diante das questões históricas, sociais, culturais - no local onde foi implantado o Projeto Porto Maravilha, localiza-se o maior porto da história da escravidão -, e na produção e musealização da exposição-obra Turvações Estratigráficas (2013), de autoria de Firmeza. Turvações reuniu memórias, desejos e violências a partir dos objetos coletados dentro e no entorno do museu. É importante ressaltar a problemática apresentada quanto à musealização dos 76 objetos da obra citada, os quais fazem parte da coleção do MAR. Por um lado, os objetos não foram criados por Yuri Firmeza, como mencionado, há um agenciamento do artista diante dessa materialidade, considerada por Firmeza e Diniz singulares, na medida que a performatividade inscrita neles narra as histórias daquele espaço. Por outro, os autores criticam a musealização desses vestígios, uma vez que há uma objetificação desses escombros e vidas. Doravante, seus argumentos consideram que os objetos performam a ruína e, quando parte de uma coleção, apresentam a possibilidade de que o museu esteja atento e acompanhe esses processos dos quais faz parte.

\section{O museu performa}

Diante da diversidade de abordagens conceitos e interpretações, duas dimensões de performatividade são perceptíveis nos textos reunidos para o dossiê Musealização da performatividade em coleções públicas e privadas. A primeira inquieta-se com o fenômeno próprio da performance enquanto linguagem cortejada pelo sistema das artes visuais, cujo protagonismo dos museus na constituição de coleções permanece inalterado. A segunda busca explorar a performatividade como fenômeno operatório para além da performance, relacionando-a às contingências de uma ação sobre a materialidade, em diferentes dimensões da prática museológica (escolhas curatoriais, condições de expositividade, percepção e mediação da produção artística pelo documento vestigial etc).

Tais dimensões atravessam todos os textos em diferentes escalas de aproximação e distanciamento. Numa leitura transversal do conjunto dos artigos selecionados para este dossiê destacam-se as narrativas similares e distintas das autoras e dos autores sobre a performatividade, como um gesto, como a 
efemeridade, como a transformação das instituições, como a transposição de obra para documento - e vice-versa -, como elemento inscrito na imaterialidade, como as reivindicações dos grupos sociais, como algo que evoca a continuidade, a mudança dos processos e a problematização das relações entre obras e museus.

Desta forma, os textos apresentados no dossiê analisam tanto as noções de musealização quanto de performatividade, buscando promover uma discussão que permeia as práticas museológicas frente à cultura (i)material, às ações artísticas efêmeras e transitórias, às construções de narrativas. Demonstrando os agenciamentos entre as intenções de sujeitos, grupos sociais, instituições, a partir da performatividade da musealização, em seu ciclo de produção de sentidos e de narrativas contínuos, nas reiterações e rompimentos entre teorias e práticas. Ou seja, o que une tais textos é a premência em debater os dissensos entre o Tempo do performativo e o Tempo do musealizado.

Diante de todas essas temporalidades dissonantes, resta-nos agradecer às autoras e aos autores que nos presentearam com seu trabalho nesses tempos insólitos. Nossa gratidão aos revisores, digramadores e pareceristas, que nos ajudaram na construção deste dossiê. Em especial, a editora Ana Lúcia de Abreu Gomes e aos demais membros da equipe editorial, que acolheram com generosidade a proposta. Para concluirmos, não nos furtemos, ainda, de compreender que cada texto presente revela um sentido de museu, um conceito distinto de como os espaços museológicos são compreendidos. Em sua completude, o dossiê performa distintas formas de interpretar e criticar os museus do presente e planejar e sonhar com outras formas de musear. Assim temos: 0 museu que separa a obra de arte do artista "como um ato autoritário e imperialista” (Myrto Kakara); o museu que, ainda, se recusa a expor "a arte de mulheres, sobretudo aquelas com trabalhos radicais e subversivos" (Daniela Labra); o museu que necessita debater às mudanças profundas que orientam "normas que ditam sexualidade e gênero" (Marisa Mokarzel); o museu que se torna atuante, "ao transformar a convencional necessidade de autonomia da obra em relação ao artista" (Daniela Martins). Enfim, o museu aberto a enfrentar as "flutuações e aos seus fantasmas" (Daniela Salazar), entre tantos outros “museus” possíveis. Instituições verdadeiramente democráticas, capazes de responder e resistir às políticas de apagamento, de sofrimento, de morte e de destruição, que reiteradamente nos proíbem de performar a vida. 